\title{
Nanocharacterization of metallic thin films deposited on different substrates
}

\author{
Violeta V. Merie ${ }^{1, *}$, Nicolae V. Burnete ${ }^{2}$, Corina BÎRleanu $^{2}$, Marius Pustan $^{2}$ \\ ${ }^{1}$ Technical University of Cluj-Napoca, Faculty of Material and Environmental Engineering, 103-105 Muncii Bvd., \\ Cluj-Napoca, Cluj county, Romania \\ ${ }^{2}$ Technical University of Cluj-Napoca, Faculty of Machine Building, 103-105 Muncii Bvd., Cluj-Napoca, Cluj county, \\ Romania
}

\begin{abstract}
The purpose of this study was to determine the influence of different substrates ( 445 steel, polycarbonate, glass) on the topography as well as tribological and mechanical properties (nanohardness, modulus of elasticity and friction force) of aluminum, gold and silver thin films. The 3D image analysis showed a strong influence of the substrate material on the topography of the studied thin films with no certain variation rule. Using the Oliver and Pharr method for determining nanohardness it was observed that, the smallest values were obtained for the thin films deposited on plastic substrate, followed by glass and C45 steel, regardless of the deposited material. The determination of the modulus of elasticity was done using the Hertzian method. The obtained results showed that the highest values of this parameter were obtained for the films deposited on plastic substrate, while the lowest values depended on both the deposited material and substrate. Friction force analysis for aluminum and gold showed a significant impact of the substrate material, with more constant values for gold. As a consequence, one must pay a particular attention when choosing the material for the substrate on which the thin films are deposited.
\end{abstract}

Keywords: metallic thin films; topography; nanohardness; friction force; modulus of elasticity

\section{Introduction}

Different materials obtained as thin films by means of physical or chemical vapor deposition methods or other technologies can be used for manufacturing microelectronic and microelectromechanical systems (MEMS). Aluminum [1-6], gold [7-12] and silver [13-18] are used in microelectronics and MEMS due to their physical, optical, mechanical, electric and/or magnetic characteristics. Even though the density of these three materials differs significantly from each other: $2.69 \mathrm{~g} / \mathrm{cm}^{3}$ (for aluminum) and $19.32 \mathrm{~g} / \mathrm{cm}^{3}$ (for gold), their Vickers hardness is quite close (15 HV to $25 \mathrm{HV}$ ). The melting point of the three materials ranges between $660{ }^{\circ} \mathrm{C}$ (for aluminum) to $1064{ }^{\circ} \mathrm{C}$ (for gold), while their modulus of elasticity (for the bulk material) varies between $68 \mathrm{GPa}$ (aluminum) and 77.2 GPa (gold). So, even though the physical properties of aluminum, gold and silver differ

*E-mail: violeta.merie@stm.utcluj.ro significantly, the mechanical characteristics of these materials are quite close.

Thin films for microelectronics and MEMS applications can be deposited using different methods such as thermal evaporation, magnetron sputtering, laser ablation, ion-beam deposition, RF reactive sputtering, plasma assisted CVD (chemical vapor deposition) and so on. Researchers are trying either to establish the deposition parameters that assure superior properties of thin films or to find out new methods for elaborating thin films that can be used for MEMS applications. The characterization of these materials is frequently done by the atomic force microscopy technique. This type of characterization allows determining their mechanical, tribological, electrical or magnetic properties at nanoscale. The characteristics of the materials obtained in this way are influenced by many factors specific to both the substrate and the deposition parameters. The substrate material, its topography, temperature and bias voltage lead to the elaboration of thin films with different properties. The 
presence of a buffer layer between the substrate and the thin film often leads to better characteristics of the deposited films. This study gives an overview of three metallic thin films (Al, Ag, Au) deposited using thermal evaporation. Atomic force microscopy investigations were performed to determine the topography as well as the tribological and mechanical properties of the films.

\section{Experimental}

The aluminum, gold and silver thin films were deposited by thermal evaporation on different substrates using evaporation materials with purity of $99.99 \%$. Three different materials were used as substrates, namely C45 steel, plastic (polycarbonate) and glass. After cutting, grinding and polishing the steel substrate was submerged in an ultrasound alcohol bath (99.9\% purity) for cleaning. Then it was dried under air jet. The polycarbonate and glass substrates were only cleaned and dried. The average roughness of the substrates was measured using an AFM which provided the following $\mathrm{R}_{a}$ values: $0.4 \mathrm{~nm}$ for glass, $41.2 \mathrm{~nm}$ for steel and $53.8 \mathrm{~nm}$ for plastic. The parameters at the beginning of the deposition process (pressure, substrate temperature, type of resistance heated source, filament current, distance between the substrate and the resistors) were the same for all substrates. The deposition was done under vacuum $\left(6.65 \times 10^{-4} \mathrm{~Pa}\right)$ using a filament current of $60 \mathrm{~A}$ to $80 \mathrm{~A}$. The distance between the substrate and the deposition material was kept constant at $50 \mathrm{~mm}$. The resulting thin film thickness was $0.7 \mu \mathrm{m}$ for all materials. The deposition was performed at room temperature $\left(22^{\circ} \mathrm{C}\right)$ but, due to the deposition process, a small increase of the substrate temperature was noticed (up to $57^{\circ} \mathrm{C}$ ). However, this change in temperature had a negligible effect on the properties of the deposited films.

The influence of the substrate on the topography and the mechanical properties of aluminum, gold and silver thin films was studied in order to analyze if the substrate has an effect on the properties of the deposited films [6, 11, 13]. Atomic force microscopy (AFM) investigations were performed on an XE-70 AFM (from Park Systems) in

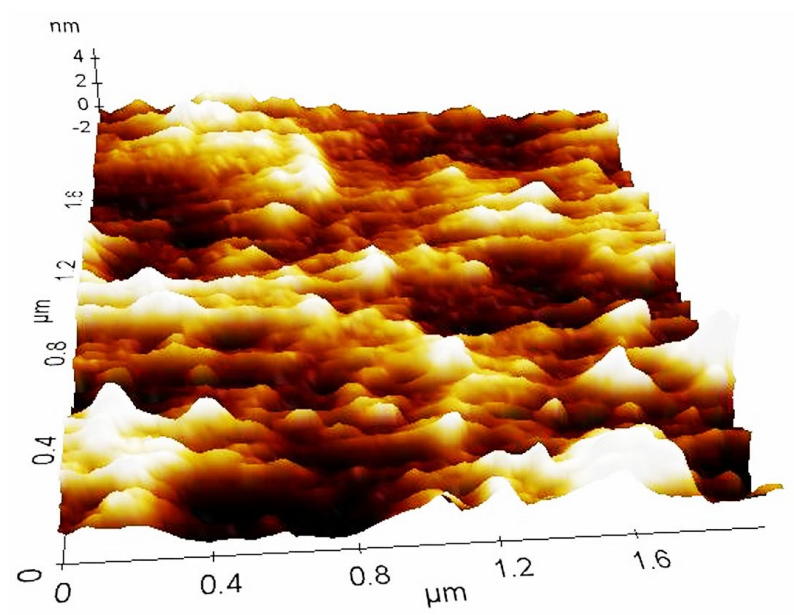

(a)

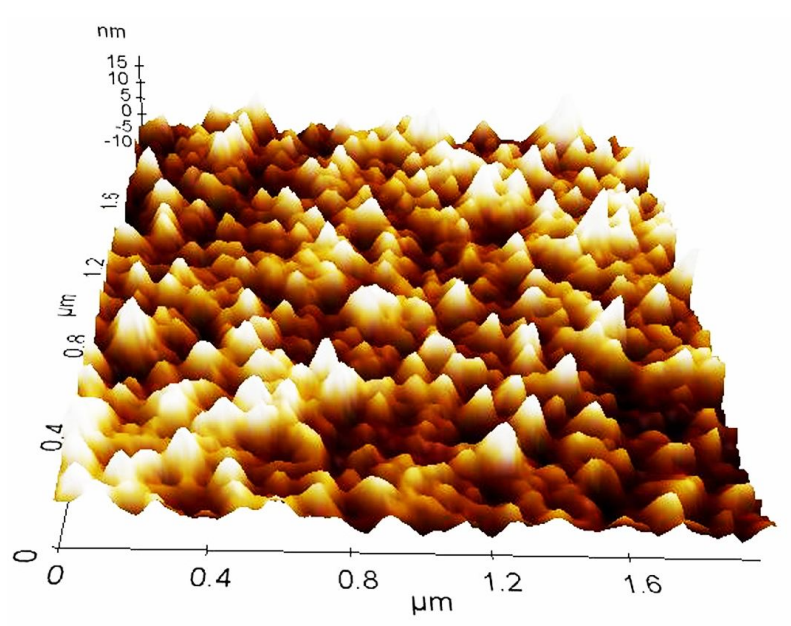

(b)

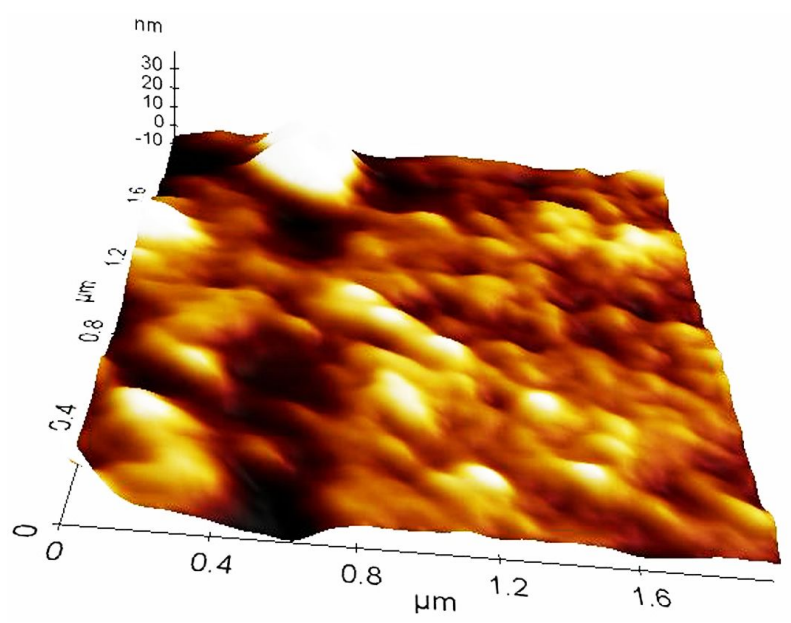

(c)

Fig. 1. 3D images of the (a) aluminum, (b) gold and (c) silver thin films deposited on glass substrates. 
a clean room. The tests were carried out at room temperature and the relative humidity of $30 \%$. The software employed for the interpretation of the achieved data was the XEI Image Processing Tool for scanning probe microscope (SPM) data. The topographical and tribological characteristics of the deposited films were determined using a NSC36/Tipless/Cr-Au cantilever. According to the manufacturer, the AFM tip is a n-type silicon cantilever with the following dimensions: thickness $-1 \mu \mathrm{m}$, width $-32.5 \mu \mathrm{m}$ and length $-110 \mu \mathrm{m}$. The mechanical properties were determined by nanoindentation tests using a TD21562 nanoindenter. The characteristics of this indenter were: cantilever stiffness $-144 \mathrm{~N} / \mathrm{m}$, tip radius $25 \mathrm{~nm}$, tip height $-109 \mu \mathrm{m}$, tip thickness $-24 \mu \mathrm{m}$, and cantilever length $-782 \mu \mathrm{m}$.

\section{Results and discussions}

Topography of the deposited thin films was one subject of performed studies. 3D images of aluminum, gold and silver thin films deposited on glass substrates are presented in Fig. 1. Even for the same substrate, significant variations of the surface topography can be observed. The surfaces of the gold thin films show more asperities compared to the aluminum surfaces while the silver thin films are characterized by smoother surfaces. We assume that the topography of these films is strongly influenced by the substrate topography and the growth mechanism, which is specific to each material. The same effect was observed when the deposition was done on plastic or steel substrates. For topography assessment of the deposited films, with respect to the nature of the substrate, 3D images of the aluminum thin films deposited on glass, plastic and C45 steel substrates are given in Fig. 2. The topography of the substrate has a very important impact on the topography of the deposited films. It is necessary to take into account the roughness and the machinability of the substrate when opting for a certain substrate material. Smoother surfaces of the deposited thin films can be obtained if the substrate roughness is small and the substrate machinability is as good as possible. The same influence of the substrate on the topography of the gold and silver thin films could be observed. The average roughness of the deposited films was determined by interpreting the data collected with the AFM as a means to characterize their topography.

Fig. 3 presents an image of the XEI Image Processing Tool for SPM Data software regarding determination of this parameter for an aluminum thin film deposited on a glass substrate. The software allows the researcher to determine the values of different parameters of roughness $\left(\mathrm{R}_{\mathrm{a}}, \mathrm{R}_{\mathrm{q}}, \mathrm{R}_{\mathrm{sk}}, \mathrm{R}_{\mathrm{ku}}\right.$, etc.). The average roughness values for the studied surfaces give an overview concerning their topography.

Fig. 4 shows the fluctuation of the average roughness for aluminum (Fig. 4a), gold (Fig. 4b) and silver (Fig. 4c) thin films when the deposition process was done on glass, plastic and C45 steel substrates, respectively. The initial analysis shows that, regardless of the material that is deposited, the highest values of the topography parameter are specific to the thin films deposited on plastic substrate while the smallest values are characteristic of the thin films deposited on glass substrate. These results are backed up by the roughness of the substrates used for the films deposition. In case of the aluminum and gold thin films deposited on glass substrates, the values of the average roughness are 8 to 11 times smaller for aluminum and 4.5 to 5.6 times smaller for gold than the values determined for the thin films deposited on plastic and C45 steel substrates, respectively. Instead, for the silver thin films, the values of the average roughness determined on the films deposited on glass substrate are 2 to 3.5 times smaller than the values of the films deposited on plastic and C45 steel substrates. The values determined for the average roughness of the gold thin films were more stable than the values of the other two thin films.

The average roughness of the aluminum, gold and silver thin films varies significantly when different substrates are used (Fig. 5). The values determined for this characteristic are ranging between $0.8 \mathrm{~nm}$ and $14.9 \mathrm{~nm}$. The average roughness of aluminum thin films deposited on glass, plastic and C45 steel substrates is about $0.8 \mathrm{~nm}, 8.7 \mathrm{~nm}$ and $6.9 \mathrm{~nm}$, respectively. In case of gold thin films, the average roughness of the films deposited on glass, 


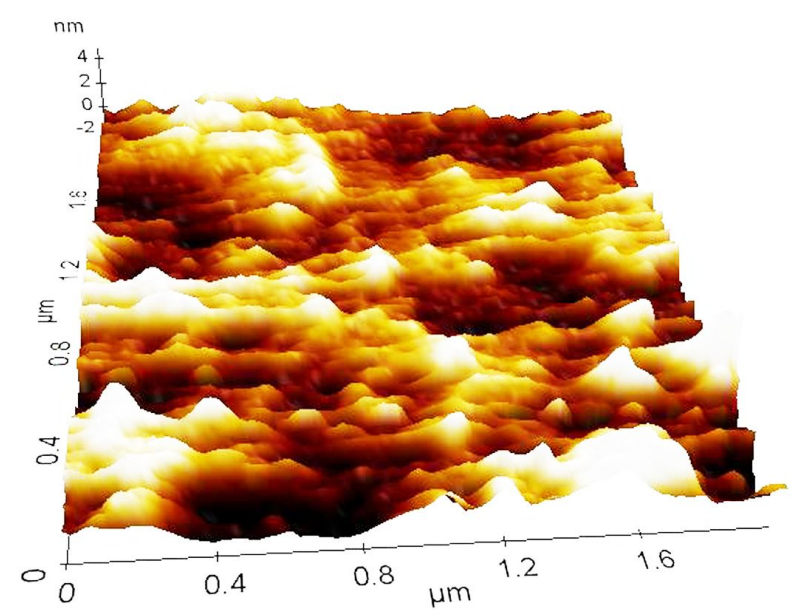

(a)

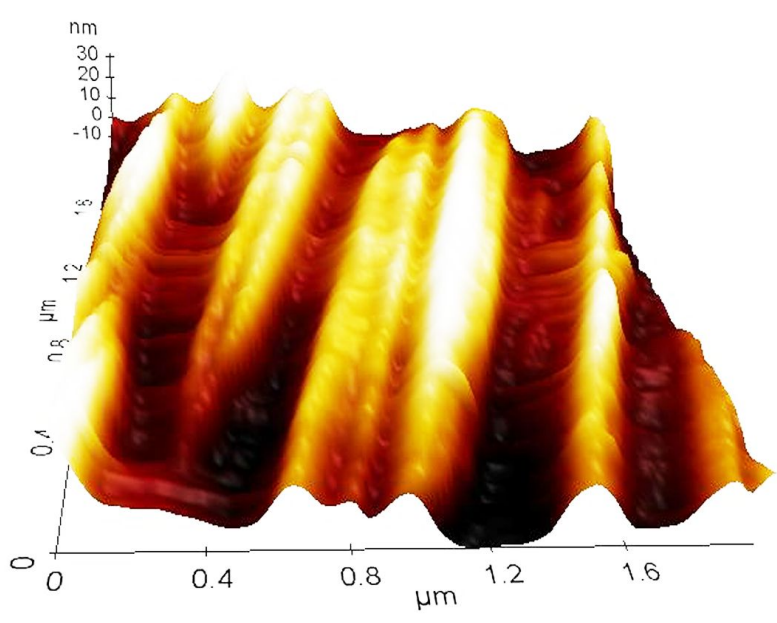

(b)

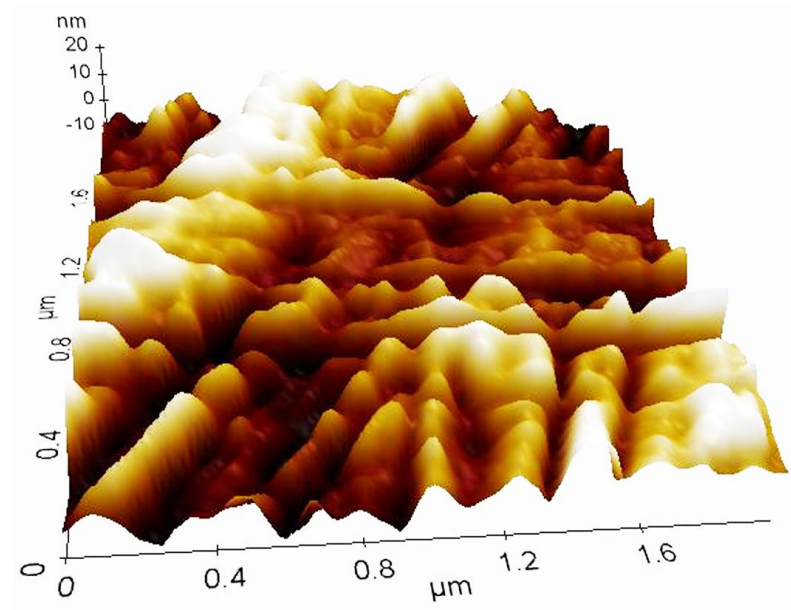

(c)

Fig. 2. 3D images of the aluminum thin films deposited on (a) glass, (b) plastic and (c) C45 steel substrates.

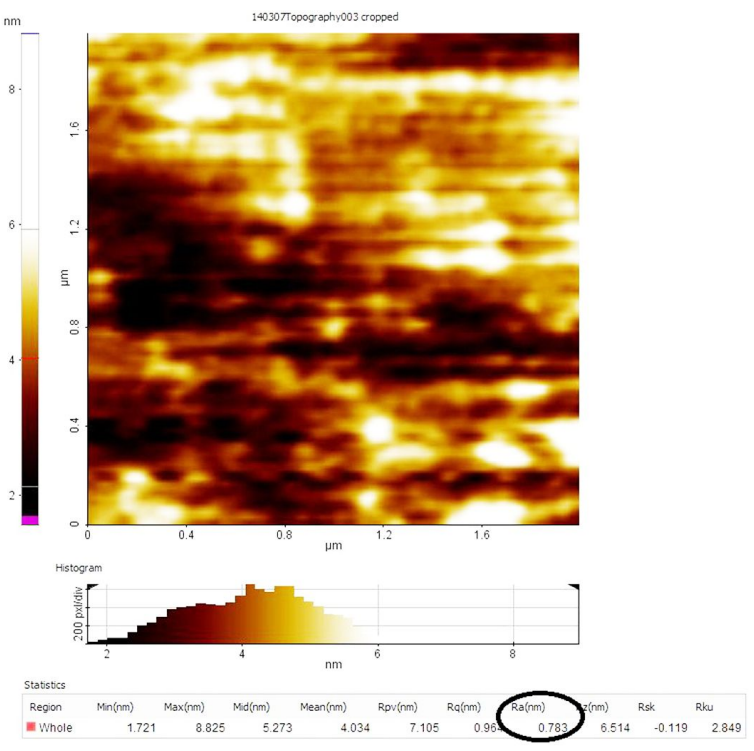

Fig. 3. Image of the XEI Image Processing Tool for SPM Data software for determining the roughness parameters of an aluminum thin film deposited on a glass substrate.

plastic and C45 steel substrates is about $2.7 \mathrm{~nm}$, $14.9 \mathrm{~nm}$ and $12 \mathrm{~nm}$, respectively. Instead, the average roughness of the silver thin films deposited on the glass, plastic and C45 steel substrates is about $2.9 \mathrm{~nm}, 10.4 \mathrm{~nm}$ and $6.0 \mathrm{~nm}$, respectively. The obtained results indicate a significant impact of substrate material on the topography parameters of the deposited thin films. This impact is more evident for the aluminum thin films as the average roughness is about 10 times lower for the films deposited on glass substrates compared to those deposited on plastic substrates.

Characterization of the thin films employed for manufacturing MEMS devices also implies determination of some mechanical properties at nanoscale. The nanoindentation tests allowed the determination of the nanohardness and the modulus of elasticity of these materials. For determining the mechanical characteristics, two different methods can be used for interpreting the collected data, namely the Oliver and Pharr method and the Hertzian method. The Oliver and Pharr method is used for determining nanohardness of thin films while the Hertzian method is used for determining their modulus of elasticity. The difference 


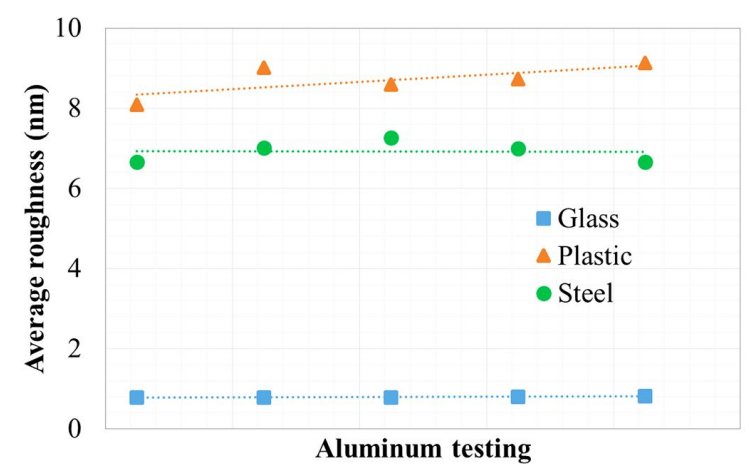

(a)

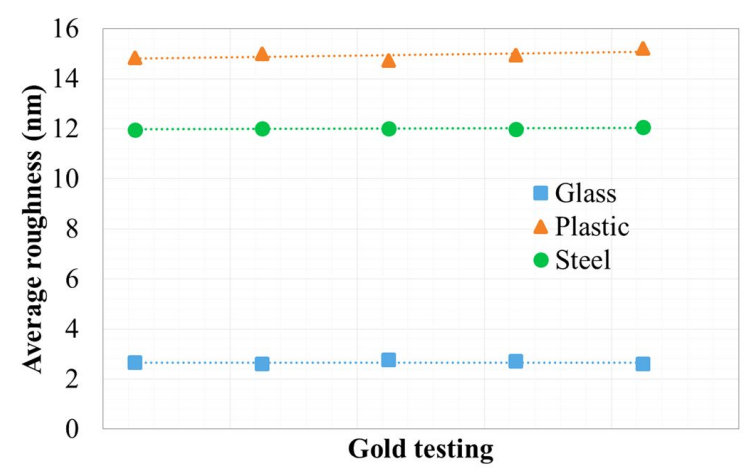

(b)

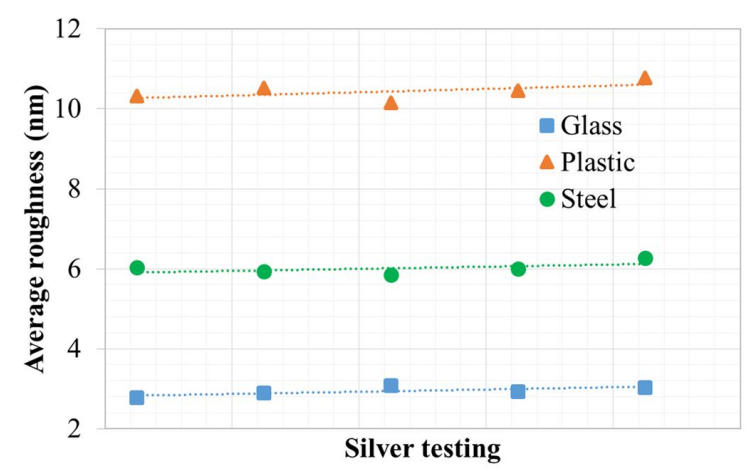

(c)

Fig. 4. Average roughness of the aluminum, gold and silver thin films deposited on glass, plastic and steel substrates.

between the two methods is that the Hertzian method assumes that there is no plastic deformation between the deposited thin films and the AFM tip regardless of the nature of the deposited material. Fig. 6 shows an image of the XEI Image Processing Tool for SPM Data software for determining the nanohardness of an aluminum thin

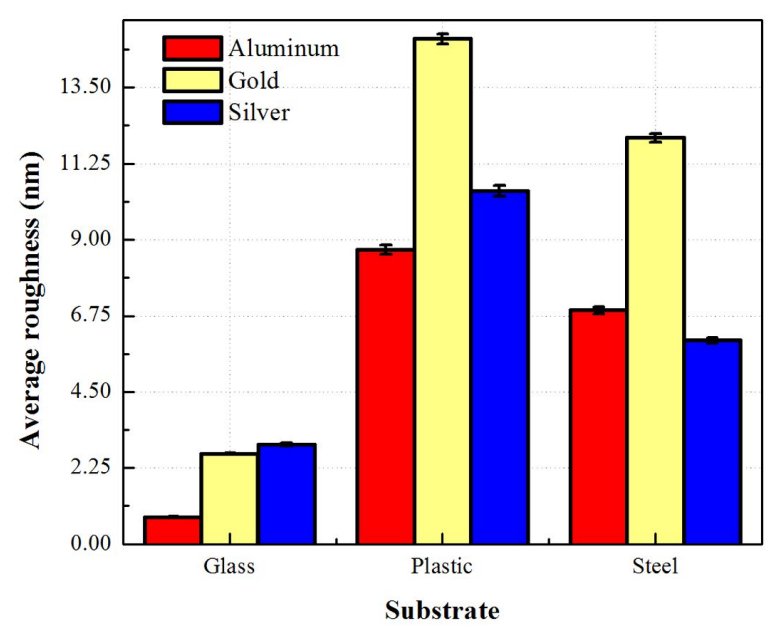

Fig. 5. Average roughness of aluminum, gold and silver thin films deposited on glass, plastic and steel substrates.

film deposited on a glass substrate. The determination of this mechanical property takes into account the values of the Poisson ratio for both the tip and the deposited thin film. The fluctuation of the nanohardness for the deposited aluminum, gold and silver thin films was studied to determine the influence of substrate material on this mechanical characteristic. When considering the same deposited material (aluminum, gold or silver), the smallest values of this parameter were obtained for the thin films deposited on plastic substrates, while the highest values of nanohardness were determined for the thin films deposited on C45 steel substrates (Fig. 7). The nanohardness of the aluminum thin films ranged between about $0.57 \mathrm{GPa}$ (for the films deposited on plastic substrates) and $0.72 \mathrm{GPa}$ (for the films deposited on C45 steel substrates). In the case of gold thin films, this mechanical property varied from $0.66 \mathrm{GPa}$ (for the films deposited on plastic substrates) to $0.94 \mathrm{GPa}$ (for the films deposited on C45 steel substrates). The silver thin films were characterized by nanohardness ranging between $0.70 \mathrm{GPa}$ (for the films deposited on plastic substrates) and $1.18 \mathrm{GPa}$ (for the films deposited on C45 steel substrates). The values determined for the three materials (aluminum, gold, and silver) deposited on glass substrates ranged between the ones determined for the thin films 
deposited on plastic and those determined for the thin films deposited on $\mathrm{C} 45$ steel substrates. The influence of substrate material on the nanohardness is most significant for the silver thin films for which, the values of this parameter increased by approximately $68.6 \%$.

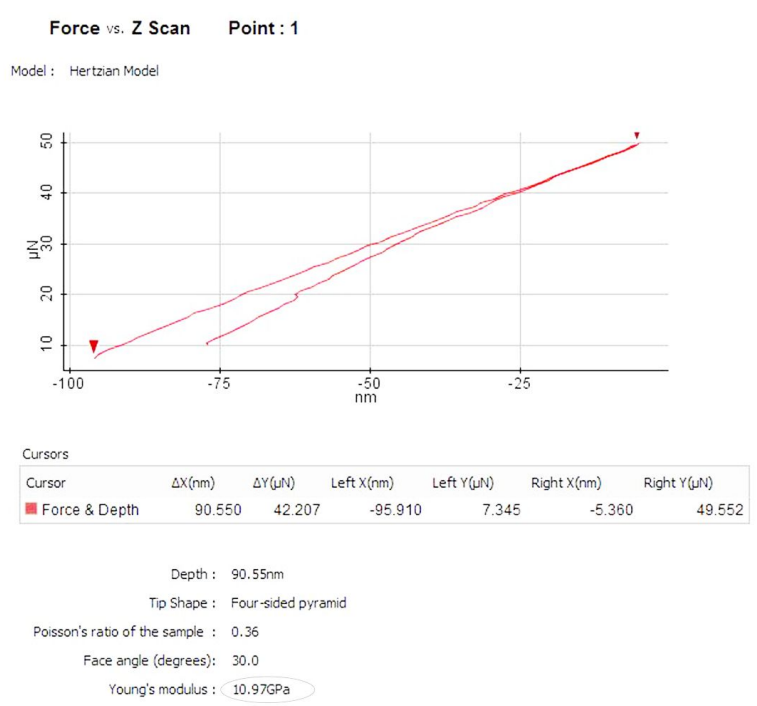

Fig. 6. Image of the XEI Image Processing Tool of SPM Data software for determining the nanohardness of an aluminum thin film deposited on glass substrate.

An image of the XEI Image Processing Tool for SPM Data software for determining the modulus of elasticity for an aluminum thin film deposited on glass substrate is given in Fig. 8. The values of this mechanical characteristic are influenced by the tip shape, the face angle of nanoindenter and the Poisson ratio of deposited thin film. The variation of the modulus of elasticity for the aluminum, gold and silver thin films deposited on glass, plastic and C45 steel was also studied (Fig. 9). The highest values of this mechanical property were achieved for the thin films deposited on plastic substrates. The smallest values for aluminum and gold were attained when the films were deposited on C45 steel, and for silver when the films were deposited on glass substrates. When discussing about the aluminum thin films, the modulus of elasticity varied between $9.24 \mathrm{GPa}$ (films deposited on C45 steel substrate) and $12.94 \mathrm{GPa}$ (films deposited on plastic substrate). The interval in which the modulus of elasticity varied for the silver thin films is larger than for the aluminum films, its values ranged between $14.33 \mathrm{GPa}$ (films deposited on glass substrate) and $25.77 \mathrm{GPa}$ (films deposited on plastic substrate). The determined values of this mechanical characteristic for the gold thin films are between $13.03 \mathrm{GPa}$ (films deposited on C45 steel substrate) and $15.32 \mathrm{GPa}$ (films deposited on plastic substrate).

As expected, the experimental results obtained for the investigated thin films by nanoindentation are different from the values provided in the literature for bulk materials [20, 21]. Table 1 contains the values for hardness and modulus of elasticity obtained by nanocharacterization of the films deposited on a steel substrate and those of the bulk materials. The differences between the values obtained by nanocharacterization compared to those of the bulk materials are due to several causes, like: measurement at macroscale compared to the one at nanoscale, grain size, fabrication method, etc. $[21,22]$. In this case, the deposition method was the same for all materials $(\mathrm{Au}, \mathrm{Ag}, \mathrm{Al})$. It was noticed that the increase in hardness for the aluminum and silver thin films compared to the bulk material hardness is similar (approximately 4.85 times), whereas for gold this increase was only 3.8 times. While the hardness value increased for all thin films compared to the bulk materials, their modulus of elasticity decreased. The smallest variation (about 4.08 times) was noticed for silver, followed by gold (5.92 times) and aluminum (7.36 times).

The friction force of thin films can be determined using the lateral mode of AFM investigations according to the following formula [19]:

$$
F_{f}=\frac{d_{z} \cdot r \cdot G \cdot h^{3} \cdot b}{l^{2} \cdot s}
$$

where $d_{z}$ represents the tip deflection, $r$ is a constant, $G$ is shear modulus $\left(\mathrm{G}=50.92 \times 10^{-3} \mathrm{~N} \cdot \mu \mathrm{m}\right.$ for silicon), $r=0.33, h, b$, and 1 are the dimensions of the cantilever used for the nanocharacterization of the films, while $\mathrm{s}$ is tip height. The fluctuation of the friction force for the aluminum and gold thin films deposited on glass, plastic and C45 steel substrates is graphically given in Fig. 10. 
Table 1. Properties of aluminum, gold and silver thin films deposited on steel substrates at nanoscale and at macroscale

\begin{tabular}{lcccccc}
\hline \multirow{2}{*}{ Property } & \multicolumn{2}{c}{ Aluminum } & \multicolumn{2}{c}{ Gold } & \multicolumn{2}{c}{ Silver } \\
\cline { 2 - 7 } & nano & bulk & nano & bulk & nano & bulk \\
\hline \hline Hardness [GPa] & 0.72 & 0.147 & 0.94 & 0.245 & 1.18 & 0.245 \\
Modulus of elasticity [GPa] & 9.24 & 68.0 & 13.03 & 77.2 & 18.64 & 76.0 \\
\hline
\end{tabular}

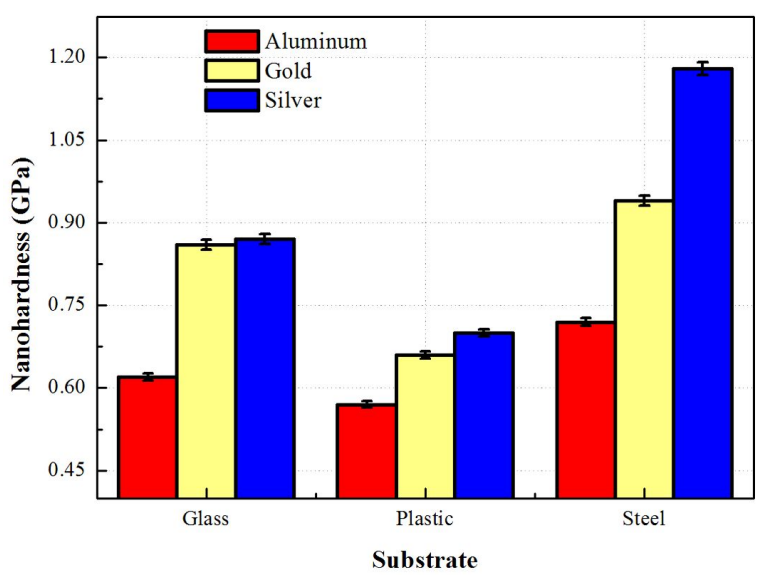

Fig. 7. The nanohardness of the aluminum, gold and silver thin films deposited on glass, plastic and steel substrates.

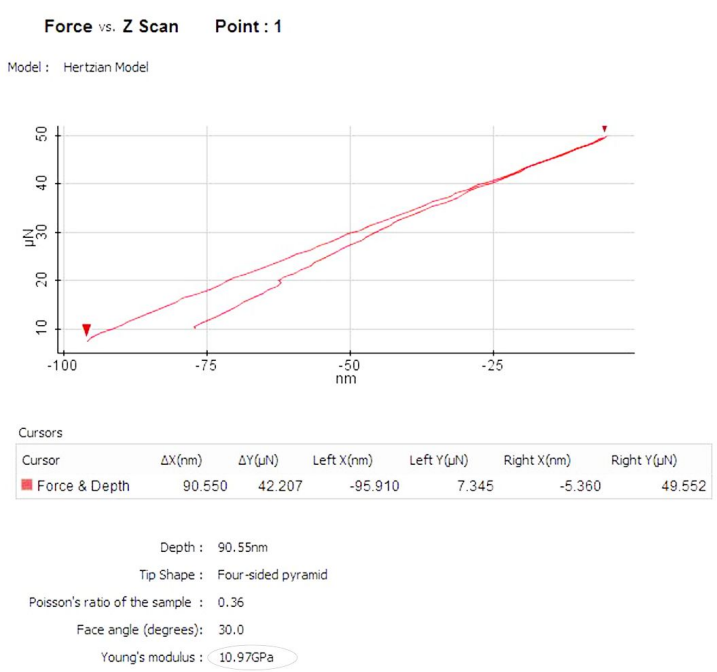

Fig. 8. Image of the XEI Image Processing Tool of SPM Data software for determining the modulus of elasticity of an aluminum thin film deposited on glass substrate.

A significant impact of the substrate material on the friction parameter of these films is noticeable.
For both deposited materials, the highest values of the friction force were determined on the films deposited on $\mathrm{C} 45$ steel substrates. The friction force of aluminum thin films deposited on $\mathrm{C} 45$ steel substrates is about 6 to 12 times higher than the friction force of aluminum thin films deposited on plastic or glass substrates. Instead, the friction parameter of the gold thin films deposited on C45 steel substrates is about 4 to 8 times higher than the friction force of aluminum thin films deposited on plastic or glass substrates. The gold thin films are characterized by more constant values of this characteristic in comparison with the aluminum thin films.

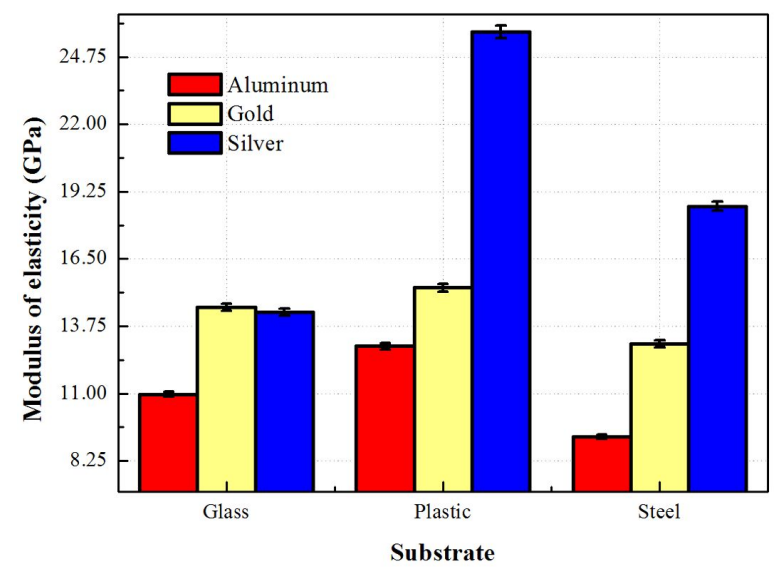

Fig. 9. The modulus of elasticity of aluminum, gold and silver thin films deposited on glass, plastic and C45 steel substrates.

\section{Conclusions}

The paper presents the analysis of the substrate effect on the mechanical and tribological properties of some metallic thin films. For this study, aluminum, gold and silver thin films were deposited by thermal evaporation on three different substrates, namely glass, C45 steel and plastic. 


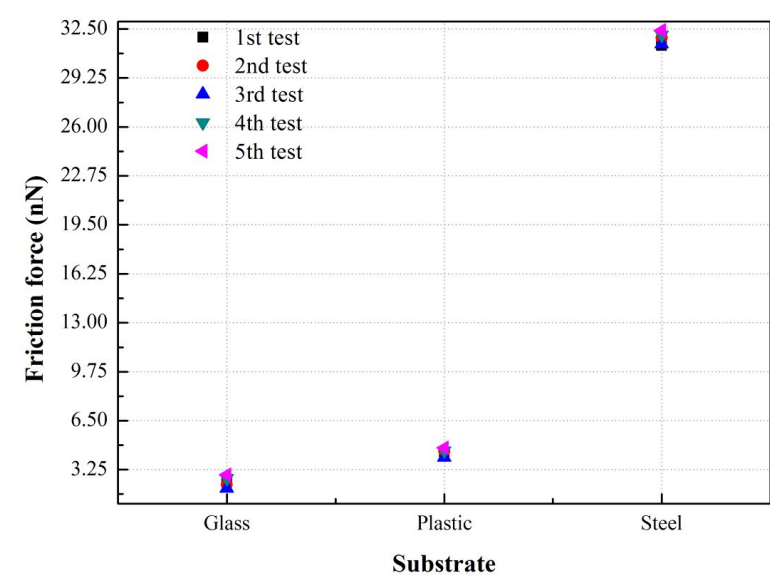

(a)

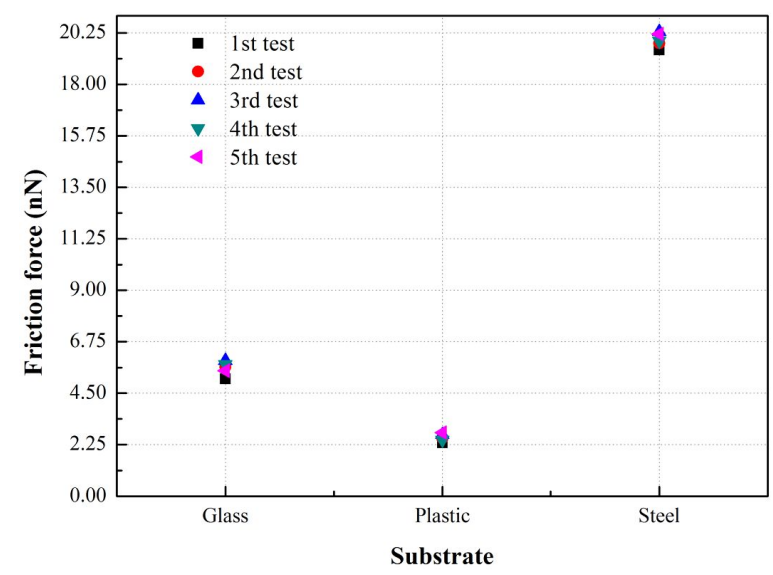

(b)

Fig. 10. The fluctuation of the friction force for the (a) aluminum and (b) gold thin films deposited on glass, plastic and C45 steel substrates.

Analysis of obtained data in terms of topographical and mechanical characteristics of aluminum, gold and silver thin films deposited on the three substrates revealed a major impact of substrate material on the properties mentioned before. The substrate topography has a strong influence on the topography of all deposited thin films. We can conclude that:

- the smallest roughness was obtained for all three metallic thin films deposited on glass the substrate with the lowest $\mathrm{R}_{a}$ value;

- the mechanical properties, namely the hardness and modulus of elasticity, determined at nanoscale differ significantly compared to the bulk materials. While the hardness at nanoscale increased several times for each material, the modulus of elasticity showed a stronger decrease;

- the highest friction force values were obtained in all cases for the films deposited on the $\mathrm{C} 45$ steel substrate.

We assume that the differences in these characteristics occur due to the surface energy (which differs from one film to another), the bonding between the substrate and the deposited material and last but not least, due to the growing mechanism that is specific to each film. Therefore, one must pay a particular attention, when choosing a material for the substrate on which the thin films are deposited.

\section{References}

[1] Peng P., Liao G., Shi T., Tang Z., Gao Y., Appl. Surf. Sci., 256 (2010), 6284.

[2] Kubo H., Ciappa M., Masunaga T., Fichtner W., Microelectron. Reliab., 49 (2009), 1278.

[3] Avilés F., Ceh O., Oliva A.I., Surf. Rev. Lett., 12 (2005), 101

[4] KAng Y.S., Ho P.S., J. Electron. Mater., 26 (1997), 805.

[5] Jiang L.M., DU Y.J., Jia J., Lai L.J., Zhou H., ZHU L.M., TIAN Z.W., TIAN Z.Q., ZHAN D., Electrochem. Commun., 33 (2013), 119.

[6] Merie V.V., Pustan M.S., Bîrleanu C., NeGREA G., Proc. $13^{\text {th }}$ Eur. Conf. on Spacecraft Struct., Mater. Environ. Test., 727 (2014).

[7] Han S.W., LEE H.W., LEE H.J., KIM J.Y., KIM J.H., OH C.S., ChoA S.H., Curr. Appl. Phys., 6S1 (2006), 16.

[8] Khaleeq-UR-Rahman M., Bhatti K.A., Rafique M.S., Anjum S., Latif A., Anjum M., Ahsan A., OZAIR H., Vacuum, 85 (2010), 353.

[9] Prószyński A., Chocyk D., GŁadyszewski G., Optica Appl., 39 (2009), 705.

[10] Okman O., Kysar J.W., J. Alloy. Compd., 509 (2011)

[11] Merie V., Pustan M., Bîrleanu C., Negrea G., BelCiN O., Adv. Eng. Forum, 13 (2015), 59.

[12] Raffa V., Mazzolai B., Mondini A., Mattoli V., Menciassi A., Dario P., Sens. Actuat. B, 122 (2007), 475.

[13] Merie V., Pustan M., Bîrleanu C., Negrea G., Appl. Mech. Mater., 658 (2014), 329.

[14] Hsu F.C., Wang Y.T., Cheng Y.C., Tong C.J., Lin M.T., Thin Solid Films, 570 (2014), 262.

[15] NAKANishi Y., Kato K., Омото H., YONEKURA M., Thin Solid Films, 532 (2013), 141. 
[16] Shinde N.M., LoKhande A.C., Bagi J.S., Lokhande C.D., Mater. Sci. Semicond. Process., 22 (2014), 28.

[17] Cao Y., Allameh S., Nankivil D., Sethiaraj S., Otiti T., Soboyejo W., Mater. Sci. Eng. A, 427 (2006), 232.

[18] Estrada-Raygoza I.C., Sotelo-Lerma M., Ramírez-Bon R., J. Phys. Chem. Solids, 67 (2006), 782.

[19] Merie V. V., Pustan M. S., Bîrleanu C., Negrea G., IOP Conf. Series: Mater. Sci. Eng., 64 (2014).
[20] ASM HANDBOOK, Mechanical testing and evaluation, Vol. 8, 2000.

[21] Han S. W., LeE H. W., LeE H. J., Kim J. Y., Kim J. H., Он C.S., ChoA S.H., Curr. Appl. Phys., 6 (2006), e81.

[22] Bhushan B., Wear, 259 (2005), 1507.
Received 2016-11-19

Accepted 2019-04-23 